\section{THE FORMS OF SEEDLINGS: THE CAUSES TO WHICH THEY ARE DUE ${ }^{1}$}

SIR JOHN LUBBOCK commenced the lecture with some general remarks on the innumerable types of foliage among mature plants and the causes to which we might refer their various forms, the breadth of some and narrowness of others, the differences of position, the differences of length in conifers, \&c. He said that these considerations had led him to study the cotyledon : or first leaves of seedlings. Cotyledons do not present such extreme differences as leaves; nevertheless, they afford a very wide range. Some are broad, some narrow, some are long, some short, some are stalked, some sessile, some lobed, some even bifid or trifid. At first sight these differences seem interminable, and it might appear hopeless to attempt to explain them. Sir John Lubbock, however, pointed out, as regards many species, taking especially the commonest plants, such as the familiar mustard and cress, the beech, sycamore, pink, chickweed, \&c., the conditions of their formation and growth, and it is beautiful to see the various reasons to which the differences are due, gradually unfolding themselves; the same result being sometimes brought about by very different circumstances-emargination of the cotyledons, for instance, being due to at least six different causes. He mentioned one curious peculiarity in the seedling of a species allied to our common mistletoe. It is a parasitic species, and its fruit, like that of the mistletoe, is somewhat viscid, so that it adheres to any plant on which it falls. But, even if it reaches the plant on which it grows, it may light on an unsuitable position-say, for instance, a leaf. What then happens? The radicle elongates for about an inch, and then develops on its tip a flattened disk, which applies itself to the plant. If the situation be suitable, there it grows; if not, the radicle straightens itself, tears the berry from the spot where it is lying, curves itself, and then brings the berry down on to a new spot. The radicle then detaches itself, curves in its turn, and thus finds a new point of attachment. We are assured that this has been seen to happen several times in succession, and that the young plant thus seems enabled to select a suitable situation.

The form of the cotyledons, or seed-leaves, depends greatly on that of the seeds, long narrow seeds naturally, in most in stances, producing embryos with narrow cotyledons. The cases, however, which can be so simply accounted for are comparatively few. Many plants with narrow cotyledons have flattened and orbicular seeds. In such species, however, the cotyledons lie transversely to the seed. An interesting case is afforded by the pink family, where the pink itself has broad cotyledons, while the chickweed has narrow ones. In both cases the seeds are flattened and orbicular, but in the pink the seed is dorsally compressed, and the cotyledons lie in the broad axis of the seed; while in the chickweed the seed is laterally flattened, and the cotyledons lie transversely to the seed.

Another very interesting case which he gave is that of the genus Galium, to which the common "cleavers" of our hedges belongs. Here also we find some species with narrow, some with broad, cotyledons; but the contrast seems to be due to a very different cause. Galizm aparine has broad, Galium saccharatum narrow, cotyledons. So far as the form of the seed is concerned, there is no reason why the cotyledons should not be much broader than they are. The explanation may perhaps be found in the structure of the pericarp, which is thick, tough, and corky. It is very impervicus to water, and may be advantageous to the embryo by resisting the attacks of drought and of insects, and perhaps even, if the seed be swallowed by a bird, by protecting it from being digested. It does not split open, and is too tough to be torn by the embryo. The cotyledons, therefore, if they had widened as they might otherwise have done, would have found it impossible to emerge from the seed. They evade the difficulty, however, by remaining narrow. On the other hand, in Galium aparine the pericarp is much thinner, and the embryo is able to tear it open. In this case, therefore, the cotyledons can safely widen without endangering their exit from the seed. The thick corky covering of Galium saccharatum is, doubtless, much more impervious to water than the comparatively thin test of Galium aparine. The latter species is a native of our own isles, while Galium saccharatum inhabits Algiers, the hotter parts of France, \&c. May not then, perhaps, he suggested, the thick corky envelope be adapted to enable it

${ }^{1}$ Lecture at the Royal Institution, May 21, I886, by Sir John Lubbock, Bart., M.P., D.C.L., LL.D., F.R.S., M.K.I. to withstand the heat and drought. In this genus, as in many other plants, the embryo occupies only a part of the seed, being surrounded by a store of food or " perisperm." In many cases the embryo occupies the whole seed, and the cotyledons must, therefore, in large seeds, either be thrown into various folds, as in the beech, or be thick and fleshy, as in the bean or oak. The reasons for their numerous differences open up an inexhaustible variety of interesting questions. Sir John gave a great number of examples, which were rendered clearer by means of numerous diagrams of seeds and seedlings.

In conclusion, he said it might be asked whether the embryo conformed to the seed, or the seed to the embryo, and showed that, at least as regards certain species, the former was the case ; while the shape of the seed, again, might be shown to be influenced by considerations connected with the construction of the fruit. In reply to this he compared the seedlings of the sycamore and of the oak. In the sycamore, the seed is more or less an oblate spheroid, and the cotyledons, which are long and ribbon-like, being rolled up into a ball, fit it closely, the inner cotyledon being generally somewhat shorter than the others. On the other hand, the nuts of the beech are triangular. An arrangement like that of the sycamore would therefore be utterly un uitable, as it would necessarily leave great gaps. The cotyledons, however, are folded up somewhat like a fan, but with more complication, and in such a manner that they fit beautifully into the triangular nut. Can we, however, he said, carry the argument one stage further? Why should the seed of the sycamore be globular, and that of the beech triangular? Is it clear that the cotyledons are constituted so as to suit the seed? May it not be that it is the seed which is adapted to the cotyledons? In answer to this, we must examine the fruit, and we shall find that in both cases the cavity of the fruit is approximately spherical. That of the sycamore, however, is comparatively small, and contains one seed, which more or less exactly conforms to the cavity in which it lies. In the beech, on the contrary, the fruit is at least twice the diameter, and contains from two to four nuts, which consequently, in order to occupy the space, are compelled (to give a familiar illustration, like the pips of an orange) to take a more or less triangular form. 'Thus then, he said in conclusion, in these cases, starting with the form of the fruit, we see that it governs that of the seed, and that the seed again determines that of the cotyledons. But, though the cotyledons often follow the form of the seed, this is not invariably the case. Other circumstances, as I have attempted to show, inust also be taken into consideration, and we can throw much light on the varied forms which seedlings assume.

I fear you may consider that I have occupied your time by a multiplicity of details, and I wish I could hope to have made those little plants half as interesting to you as they have made themselves to me; but, at any rate, I may plead that without minute, careful, and loving study, we cannot hope in science to arrive at a safe and satisfactory generalisation.

The lecture was accompanied not only by numerous diagrams, but by specimens, kindly lent by the authorities of Kew, and by some practical illustrations.

\section{ON THE USE AND EQUIPMENT OF ENGINEERING LABORATORIES}

$A \mathrm{~T}$ the ordinary meeting of the Institution of Civil Engineers, $\mathrm{A}^{\mathrm{T}}$ on Tuesday, December 21, I886, Mr. Edward Woods, President, in the chair, the paper read was on "The Use and Equipment of Engineering Laboratories," by Prof. Alex. B. W. Kennedy, M.Inst.C.E. The author believed that it was essential for a yourg engineer to obtain his practical training, in the ordinary sense of the expression, in a workshop. But the practical training of a workshop was incomplete even on its own ground, and there appeared to be plenty of room for practical teaching such as might fairly fall within the scope of a scientific institution, and which should at the same time supplement and complete workshop experience without overlapping it. In an ordinary pupilage a young engineer did not have much opportunity of studying such things as the physical properties of the iron and steel with which he had to deal, nor the strength of those materials, nor the efficiency of the machines he used, nor the relative economy of the different types of engines, nor the evaporative power of boilers. He required such experience as might help him to determine for himself, or at least to see for himself how other people had 